\title{
A Conversation Between Kelsey Martin and Johannes Czernin
}

\author{
Kelsey C. Martin and Johannes Czernin \\ David Geffen School of Medicine at UCLA, Los Angeles, California
}

$\mathbf{J}$ ohannes Czernin, MD, talked in June with Kelsey Martin, $\mathrm{MD}, \mathrm{PhD}$, dean of the David Geffen School of Medicine and professor of Biological Chemistry and of Psychiatry and Biobehavioral Sciences at the University of California, Los Angeles (UCLA). Dr. Martin received her BA from Harvard University (Boston, MA) in English and American language and literature. She spent $2 \mathrm{y}$ as a Peace Corps volunteer in Zaire, where she became involved in public health issues. She received her medical degree and $\mathrm{PhD}$ from Yale University (New Haven, CT). She then served as a postdoctoral fellow and associate research scientist in the lab of Nobel laureate Eric Kandel at the Howard Hughes Medical Institute at Columbia University (New York, NY). In 1999, Dr. Martin became a faculty member and subsequently chair of the Department of Biological Chemistry at the David Geffen School of Medicine, where she has served as dean since 2016. Her internationally noted research has focused on the plasticity of memory function. She is a member of the American Academy of Arts and Sciences and of the National Academy of Medicine.

Dr. Czernin: Your position as dean of the David Geffen School of Medicine carries wide-ranging areas of responsibility, including health care, research, socioeconomic issues, teaching, and learning. How did your background and experience inform your overall job understanding and specifically your response to COVID?

Dr. Martin: What affected my job are all those changes that I made in my career. I love literature because characters are perfect examples of human behavior. Moving to a rural African area I initially thought I would end up in infectious disease and public health. But later I became totally fascinated by psychiatric diseases and felt that we needed to better understand how the brain works. What all this taught me is how many different perspectives there are to solving problems. It also taught me to be as open minded as I can when there's a problem - that I have to look at it from all different angles. What COVID-19 showed me is how the systems that we have set in place don't always work. We need to take a broader perspective to figure out how do solve the acute but also the long-term problems.

One of the biggest impacts that the Peace Corps had on me was to go to a place that actually had very little infrastructure for providing health care. There was no transportation infrastructure. There was no real health care. It made me aware that a health-care system is just a construction and that it's our responsibility to adapt systems to be responsive to acute and chronic health issues.

Dr. Czernin: We recently published a discussion with Johnese Spisso, the president of UCLA Health, with the goal of understanding the impact of COVID on a large health system. A group from the Memorial Sloan Kettering Cancer Center (New York, NY) just

COPYRIGHT @ 2020 by the Society of Nuclear Medicine and Molecular Imaging. published in The Journal of Nuclear Medicine their assessment of the pandemic's impact on the global U.S. health economy. I asked for this discussion with you because medical schools face different challenges. How do we adapt our behavior and standard workflows to off-campus work, learning, teaching, and research?

Dr. Martin: How do we adapt? I've been thinking a lot about how our physical environment has changed so much that it's forced a very rapid evolution of how we function as hu-

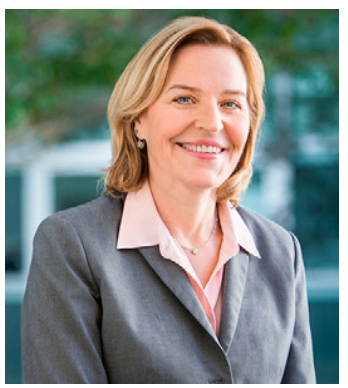

Kelsey C. Martin, MD, PhD man beings. A lot of the anxiety that's been created is explained by so much uncertainty. When you have such a rapid change in how our society functions and how our economy, health care, and educational systems work, that level of uncertainty is difficult to comprehend for humans. One of the most important ways to address it is to communicate and provide clarity over how decisions are being made. We can use technology to do this. I have been amazed by the rapid emergence of telemedicine over the last months. This has been in the works for a long time but was forced and accelerated as a way of providing health care when we can't do it in traditional ways. And that's actually quite important from a public health perspective for underserved populations who can gain access to adequate medical care. It is adaptation. In education, it's been really remarkable how quickly faculty and staff have pivoted to provide some instruction remotely. There is a little silver lining there. These technologies might provide access to educational opportunities for more people. It might democratize some of that education.

I also feel very strongly that solving the COVID-19 problem underscores the desperate need for biomedical research. We need to quickly design and execute clinical trials to identify the best therapeutics and to develop and test vaccines. COVID is a good example of how the lack of real and great investment can put us at risk. Finally, COVID made it very apparent to me that U.S. health-care systems are not closely enough aligned with public health. One of my early publications during my Peace Corps time, a training manual for health-care workers, was entitled "Budimu mBupita Buanga: Bansonsolodi," which means "an ounce of prevention is worth a pound of cure."

Dr. Czernin: Let's discuss issues related to the medical school. How has the student selection process changed?

Dr. Martin: For the coming year, there are a few changes. One is that interviews will be virtual-that's true for medical students and for residents. Other aspects will be different. For example, earlier this year the University of California medical schools came together to agree that for some of the premed prerequisites, including biology, chemistry, physics, and calculus, we would accept pass/fail 
grades because many undergraduate programs were impacted by COVID-19 in ways that made it difficult for students to get final grades in those courses.

Dr. Czernin: What about medical students who are already enrolled at UCLA? What's the policy now in terms of their campus presence?

Dr. Martin: Our fourth-year students, who are at the end of their training, stayed in most of their clinical clerkships but were not involved in the care of COVID-19 patients. We moved the thirdyear students out of the clinic and stopped the clinical work of the first- and second-year students to move everything to remote learning. This was done for a variety of reasons, including shortages of personal protective equipment. We had to create rounds that largely took place outside of patient rooms and with physical distancing.

The third- and fourth-year students are now returning to the wards. This has been a very difficult time for the students. It has indeed turned every aspect of their lives upside down. It has also raised questions about what it means to be a doctor, the kind of risks but also inspirations that come with working in a health-care setting.

Dr. Czernin: It is striking how the economic fallout of COVID is similar to the consequences of the Spanish flu 100 years ago, which also most severely affected minorities and low-income populations. That is something that needs to be recognized.

Dr. Martin: Right, this needs to be recognized and addressed. Among my main concerns for students is the impact of COVID-19 on our economy. Parents, spouses, or significant others may have for the U.S. health-care system within just 4 months. Departments will be unable to maintain high-level financial support for research. Given these dramatic losses, society, as represented by the government, has a huge responsibility. We, the people, bailed out the automobile industry, banks, savings and loans, mortgage lenders, and many more. Do you foresee a bailout of hospital systems? I ask specifically because the smaller rural hospitals that service the underserved population are at highest risk for bankruptcy. Is there a national movement toward a hospital bailout?

Dr. Martin: I have been very heartened by the fact that the National Institutes of Health is continuing to really support research activities. I actually don't know if there's a strong national movement for a bailout, but I do know that the way that we fund health care is not sustainable and that there has to be a change. My personal belief is that health care is a human right and a social service that should be provided to all human beings. And we have gotten away from that. We are going to have to navigate our way back to a system that will allow that, whether it's through a bailout or some sort of restructuring of health-care systems.

It is true that in an academic medical center the professional fees support not just research but a lot of our education. Not to have mechanisms in place to ensure that this support continues is extremely short sighted.

Dr. Czernin: There have already been more than a million health-care jobs lost during the pandemic. Layoffs disproportionately affect minorities and low-income jobs. Avoiding mass layoffs

\section{"[S]olving the COVID-19 problem underscores the desperate need for biomedical research. We need to quickly design and execute clinical trials to identify the best therapeutics and to develop and test vaccines. COVID is a good example of how the lack of real and great investment can put us at risk."}

become unemployed or may be facing increasing financial difficulties. This is an enormous struggle for many students and their families.

Dr. Czernin: Workflows have changed. Many people work from home. What kind of feedback do you get from staff? Do they like it or miss the social interaction?

Dr. Martin: It's a mixed bag. Many things can be done more productively from home. In Los Angeles, many people certainly welcome the rescued time not spent commuting. However, many of our faculty, staff, and trainees have young children who are not in school now. So, they have to work while they're also parenting at home. Others may live in a smaller home with more people, where it's difficult to find work space. So, there are large differences in terms of the ease with which staff, faculty, and trainees can work from home. There are human resources efforts to help provide childcare support for staff. Our students, graduate students, medical students, and students from other health sciences schools have come together to be available for providing childcare, running errands, and offering other help for frontline health-care workers.

Dr. Czernin: COVID has had a dramatic impact on academic research. Research America recently reported that more than $65 \%$ of research funds come from industry and $22 \%$ from the U.S. government, but that in academic health centers a large portion of research funding is generated by clinical departments. The Memorial Sloan Kettering group is reporting a $\$ 130$ billion loss would only be possible by tax increases or bailouts. Do you have specific ideas on how this system can be changed?

Dr. Martin: To address these great disparities, I believe we need to revisit funding in health care. From my perspective, a more public health approach to health care is needed. As you know well, we spend more on health care than any other nation, yet we're really not at the top in terms of outcomes.

I am a scientist. I believe in looking at the data in an openminded, unbiased way and identifying solutions. But those solutions are going to have to be reached in a way that reflects the philosophy of John Rawls, which says that if you are going to solve a problem around social justice (which is what this is) you have to put yourself behind what's called the "veil of ignorance," where you don't consider your own self-interest. I know that may sound naïve, but I don't see how we're otherwise going to get out of this situation.

Czernin: What will or should a medical school look like in 5 to 10 years?

Dr. Martin: I can tell you what I hope the medical school will look like. I took this job because I believe deeply that there are incredible opportunities at the interface of clinical medicine and research and education. I hope that those activities will come closer together-that there will be even closer communications among clinicians, scientists, and trainees to reimagine what the real pathophysiology of disease is, whether it's the social 
determinants of health or a mutation in a gene or an infectious agent. And that this collaboration results in new solutions going forward. We need to train the next generation of scientists and physicians in a way that is as inclusive of as many different points of view as possible. We will have a much more equitable medical school. I mean equitable for individuals who are working in the laboratory, in the clinic, and in the classroom.

Dr. Czernin: Is there anything else you want to add?

Dr. Martin: This is a really challenging time, with COVID-19 and with police violence and the death of George Floyd. The racism that has existed in our nation has been a very long-term pandemic. There is a real need for change. It's comforting that a lot of really (for lack of a better word) good people are out there who are dedicated to working on these problems at all different levels. As challenging as the next 3 to 5 years are going to be for academic medical centers, this is going to be an opportunity to really figure out how we will accomplish the missions of advancing science and medicine more effectively than ever before.

Dr. Czernin: Thank you very much for taking the time to talk with our readers and me. 